\title{
Effects of Elevated Temperature on Tunable Near-Zero Threshold CMOS
}

\author{
Vjekoslav Svilan \\ Department of Electrical \\ Engineering \\ Stanford University \\ 350 Serra Mall \\ Stanford, CA 94305-9515 \\ vsvilan@stanford.edu
}

\author{
James B. Burr \\ Sun Microsystems \\ 901 San Antonio Road \\ M/S MPK15-222 \\ Palo Alto, CA 94303 \\ jim.burr@eng.sun.com
}

\author{
G Leonard Tyler \\ Department of Electrical \\ Engineering \\ Stanford University \\ 350 Serra Mall \\ Stanford, CA 94305-9515 \\ len@nova.stanford.edu
}

\begin{abstract}
This paper explores functionality, performance, and energy efficiency of an 80,000 transistor, $0.35 \mu \mathrm{m}$, back-bias tunable, near-zero $V_{t h}, 32 \times 32$-bit multiplier operating at $100^{\circ} \mathrm{C}$. Compared to operation at $28^{\circ} \mathrm{C}$, performance at $V_{d d}=2.0 \mathrm{~V}$ degrades 14 percent from $188 \mathrm{MHz}$ to $162 \mathrm{MHz}$. At lower supply voltages, back bias is adjusted to minimize power dissipation as a function of operating frequency similarly to what we reported last year at $28^{\circ} \mathrm{C}$. Comparing the operating points, the same performance at $100^{\circ} \mathrm{C}$ requires about 1.5 times the power measured at $28^{\circ} \mathrm{C}$. It also requires about $1.2 \mathrm{~V}$ additional back bias and about a 20 percent increase in $V_{d d}$. The fraction of total power dissipated as leakage increases by about 1.5 times.
\end{abstract}

\section{INTRODUCTION}

An increasing number of applications, especially portable ones, are becoming limited by power, rather than performance. Reducing supply voltage [1, 2] or signal swing [3] have been shown effective in reducing power. However, to maintain performance with lower supply voltage, the transistor threshold voltage $\left(V_{t h}\right)$ also needs to be lowered [4], resulting in increased leakage power.

We have demonstrated [5] that circuits fabricated in nearzero threshold CMOS technology, combined with variable threshold CMOS (VTCMOS) techniques [6, 7, 8, 9] and operating at room temperature can achieve significant energy savings as compared to equivalent circuits fabricated in standard CMOS technology. It was also shown that tunable near-zero threshold CMOS technology offers performance advantages over standard CMOS. Unlike standard CMOS where leakage power is usually a negligible portion of the total power, we have shown that the leakage power should be a significant portion of the total power if one is to achieve minimum energy per operation.

Permission to make digital or hard copies of all or part of this work for personal or classroom use is granted without fee provided that copies are not made or distributed for profit or commercial advantage and that copies bear this notice and the full citation on the first page. To copy otherwise, to republish, to post on servers or to redistribute to lists, requires prior specific permission and/or a fee.

ISLPED'01, August 6-7, 2001, Huntington Beach, California, USA.

Copyright 2001 ACM 1-58113-371-5/01/0008 ...\$5.00.

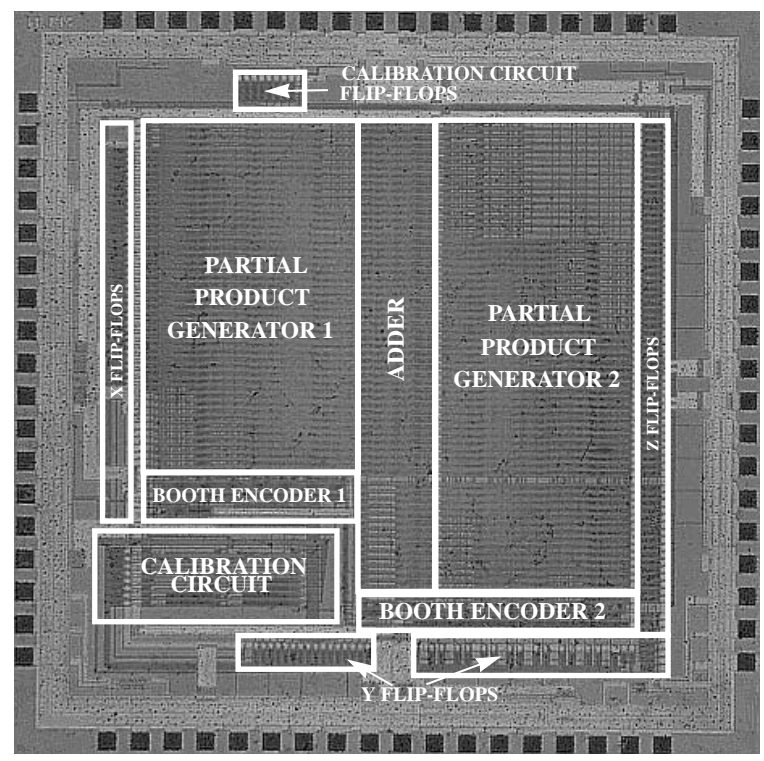

Figure 1: Chip micrograph

This paper explores the effects of elevated temperature on the functionality, speed and energy efficiency of circuits fabricated in near-zero threshold CMOS. It demonstrates that even at increased ambient temperature, back gate bias can be used to optimize the ratio of leakage and switching power and therefore achieve minimum energy per operation.

\section{CIRCUITS AND TECHNOLOGY}

A 32 x 32-bit signed integer multiplier [10] designed using dynamic, low-swing differential circuit techniques has been used as a test vehicle to measure the effects of elevated ambient temperature on functionality, speed and energy efficiency of circuits fabricated in near-zero threshold CMOS technology. The multiplier uses 4-bit Booth encoding and tree reduction by a $4-2$ adder. It was fabricated in a $0.35 \mu \mathrm{m}$ near-zero threshold process. It occupies $3.1 \times 3.1 \mathrm{~mm}$ area and contains about 80,000 transistors (Figure 1). The multiplier was tested at ambient temperatures of $28 \pm 2^{\circ} \mathrm{C}$ and $100 \pm 2^{\circ} \mathrm{C}$ measured while chip was powered-off. When the chip was operating, we observed up to an additional $6^{\circ} \mathrm{C}$ in- 


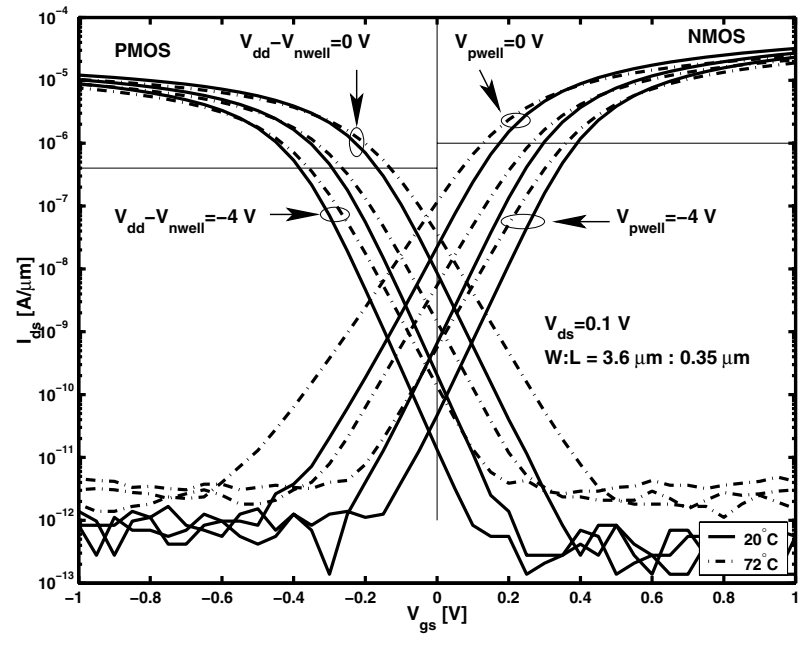

Figure 2: $3.6 \mu \mathrm{m}: 0.35 \mu \mathrm{m}$ NMOS and PMOS transistor I-V curves at $20^{\circ} \mathrm{C}$ and $72^{\circ} \mathrm{C}$ showing large threshold tunability. The curves are plotted for $V_{d d}-V_{\text {nwell }}=V_{\text {pwell }}=\{0,-2,-4\} \quad \mathrm{V}$

crease in the die package temperature caused by chip power dissipation.

Figure 2 shows $I_{d s}$ vs. $V_{g s}$ transistor characteristics of a $3.6 \mu \mathrm{m}: 0.35 \mu \mathrm{m}$ PMOS and NMOS device for back-bias $\left(V_{d d}-V_{\text {nwell }}, V_{\text {pwell }}\right)$ voltages ranging from 0 to $-4 \mathrm{~V}$ at $20^{\circ} \mathrm{C}$ and $72^{\circ} \mathrm{C}$. It demonstrates a wide range of threshold tunability which was used to balance static and dynamic power over frequency, circuit activity, effective logic depth and temperature. Degradation of drive current and subthreshold slope is observed at elevated temperature.

\section{RESULTS}

Figure 3 shows a Shmoo plot of the multiplier at $28^{\circ} \mathrm{C}$. At $28^{\circ} \mathrm{C}$ the zone of correct operation includes both filled and unfilled circles. For supply voltages of $0.8 \mathrm{~V}$ and above, the multiplier is fully functional regardless of the values of the back-bias voltages. At lower supply voltages, a balance between the two biases is required to maintain minimum values of $I_{o n N M O S} / I_{o f f P M O S}=100$ and $I_{o n P M O S} / I_{o f f N M O S}=$ 120 to ensure proper circuit operation[5]. In addition, since the NMOS transistors have lower built-in $\left(V_{\text {pwell }}=0 \mathrm{~V}\right)$ threshold voltage than the PMOS transistors, the zone of valid operation at low supply voltages is offset with respect to the diagonal. The multiplier was found to be functional down to $V_{d d}=0.16 \mathrm{~V}$.

Figure 3 also shows a Shmoo plot of the near-zero $V_{t h}$ CMOS multiplier at $100^{\circ} \mathrm{C}$. At $100^{\circ} \mathrm{C}$ the zone of correct operation is indicated by filled circles only. In general, this behavior is similar to the behavior shown at $28^{\circ} \mathrm{C}$. As the supply voltage is decreased, a balance between two biases has to be maintained to obtain correct operation. However, while at $V_{d d}=0.2 \mathrm{~V}$ and $28^{\circ} \mathrm{C}$ we found the zone of valid operation to span about $0.8 \mathrm{~V}$ in both $\left(V_{d d^{-}} V_{\text {nwell }}\right)$ and $V_{\text {pwell }}$, at $100^{\circ} \mathrm{C}$ we found only a single valid combination of $\left(V_{d d}-V_{\text {nwell }}\right)$ and $V_{\text {pwell }}$ which produced correct operation. Since increased temperature lowers the threshold voltage and therefore increases $I_{o f f}$, only at that particular location in $\left(V_{d d}=0.2 \mathrm{~V},-4 \mathrm{~V} \leq\left(V_{d d^{-}}-V_{\text {nwell }}\right) \leq 0 \mathrm{~V},-4 \mathrm{~V} \leq V_{\text {pwell }} \leq 0 \mathrm{~V}\right)$
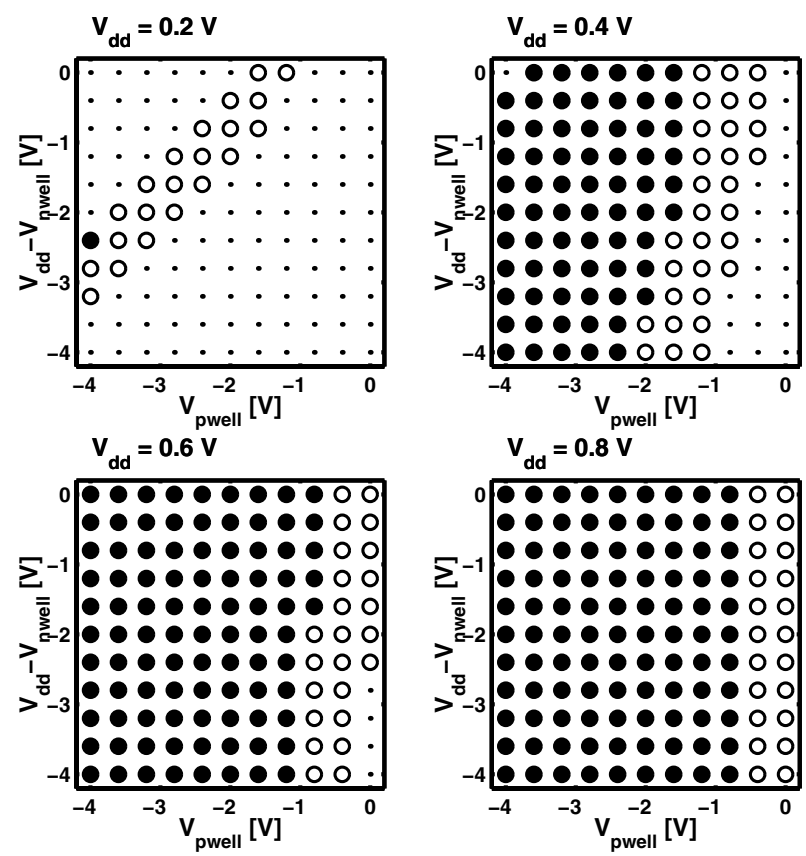

Figure 3: Multiplier Shmoo plot. Filled circles indicate correct operation both at $28^{\circ} \mathrm{C}$ and $100^{\circ} \mathrm{C}$, while unfilled circles indicate correct operation at $28^{\circ} \mathrm{C}$ only

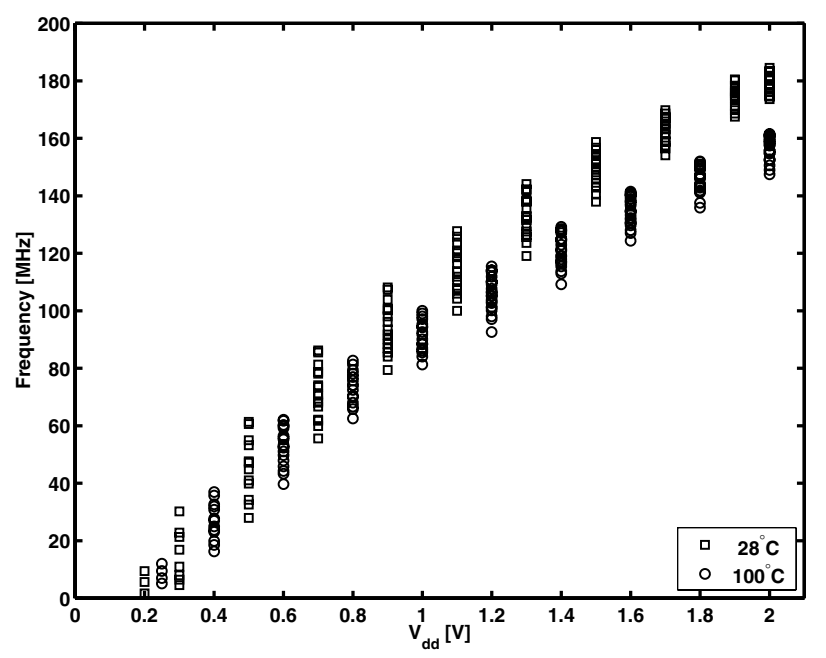

Figure 4: Multiplier frequency vs. supply voltage at $28^{\circ} \mathrm{C}$ and $100^{\circ} \mathrm{C}$ 


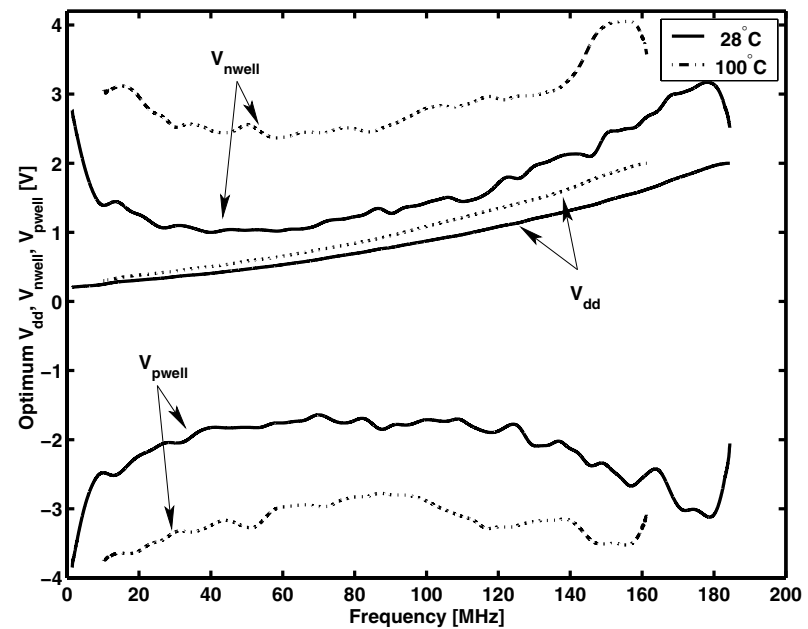

Figure 5: Optimum supply and well voltages vs. frequency at $28^{\circ} \mathrm{C}$ and $100^{\circ} \mathrm{C}$

space we are able to achieve the minimum required values of $I_{O n N M O S} / I_{O f f P M O S}$ and $I_{o n P M O S} / I_{O f f N M O S}$.

Figure 4 shows multiplier performance vs. supply voltage for both temperatures. The range of points at each value of $V_{d d}$ corresponds to various combinations of $\left(V_{d d}-V_{\text {nwell }}\right)$ and $V_{\text {pwell }}$ ranging from $(0,0)$ to $(-4,-4)$. At $28^{\circ} \mathrm{C}$ the multiplier runs at $188 \mathrm{MHz}$ at $V_{d d}=2.0 \mathrm{~V}, 136 \mathrm{MHz}$ at $V_{d d}=1.2 \mathrm{~V}$ and at $40 \mathrm{MHz}$ at $V_{d d}=0.4 \mathrm{~V}$. At $100^{\circ} \mathrm{C}$ the multiplier runs at $162 \mathrm{MHz}$ at $V_{d d}=2.0 \mathrm{~V}, 115 \mathrm{MHz}$ at $V_{d d}=1.2 \mathrm{~V}$ and at $37 \mathrm{MHz}$ at $V_{d d}=0.4 \mathrm{~V}$. The performance degradation is about 15 percent at the higher supply voltages due to decreased carrier mobility. At lower voltages the performance degradation is less than 10 percent. The smaller speed penalty at lower voltages can be attributed to improvements in performance resulting from temperature induced threshold lowering.

In low threshold CMOS, the key to achieve minimum power at the required performance is to choose the optimum ratio of leakage power to total power. For example, for the multiplier to run at $40 \mathrm{MHz}$ at $28^{\circ} \mathrm{C}$, one can choose a supply voltage ranging from 0.37 to $0.6 \mathrm{~V}$. Although a lower supply voltage may seem advantageous, it requires very low thresholds which in turn makes leakage power too large.

Figure 5 shows the supply and well voltages which result in minimum total power at the given frequency for both ambient temperatures. We observe that to run at any given frequency at $100^{\circ} \mathrm{C}$ we need to apply higher supply and well voltages than to run at $28^{\circ} \mathrm{C}$ at that same frequency. The optimum supply voltage is on average 23 percent higher at $100^{\circ} \mathrm{C}$ than at $28^{\circ} \mathrm{C}$. The majority of that increase is due to the performance degradation discussed earlier. The optimum $\left|\left(V_{d d}-V_{\text {nwell }}\right)\right|$ voltage at $100^{\circ} \mathrm{C}$ is on average $1.10 \mathrm{~V}$ higher than at $28^{\circ} \mathrm{C}$, while the optimum $\left|V_{\text {pwell }}\right|$ voltage is $1.25 \mathrm{~V}$ higher at $100^{\circ} \mathrm{C}$ than at $28^{\circ} \mathrm{C}$.

As frequency increases over about $100 \mathrm{MHz}$, we observe a gradual increase in absolute values of the optimum well voltages, indicating a need for higher thresholds. This increase compensates for decreased thresholds resulting from drain-induced barrier lowering, which is more pronounced at higher supply voltages. At the highest achievable frequencies for each ambient temperature we observe sharp

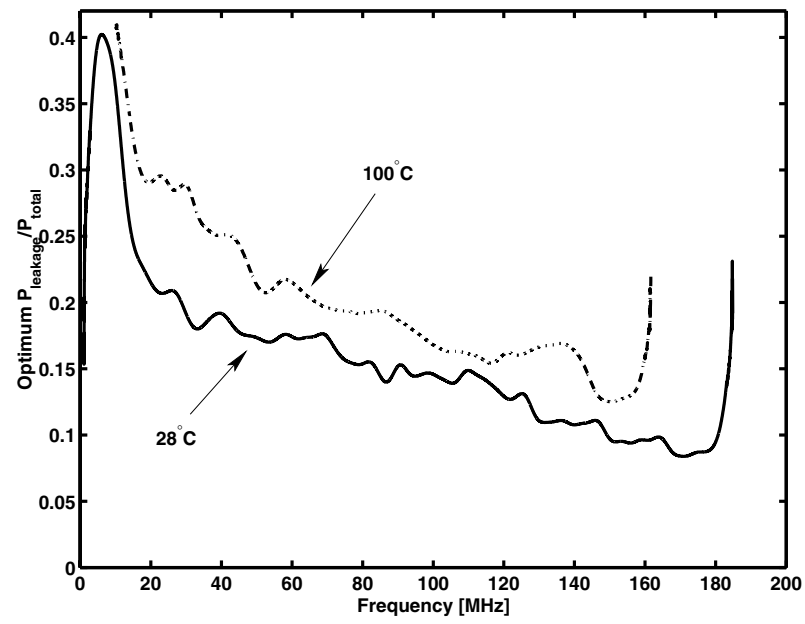

Figure 6: Optimum ratio of leakage power to total power at $28^{\circ} \mathrm{C}$ and $100^{\circ} \mathrm{C}$

decreases in the absolute values of the well voltages, indicating a need for lower thresholds. At the highest frequencies it would be more efficient to run at higher supply and threshold voltages. However, since we limited our supply voltage to $2 \mathrm{~V}$, the only way to achieve the highest frequencies is to run at maximum supply voltage and lowest thresholds.

Figure 6 gives the optimum ratio of leakage power to total power vs. frequency for both temperatures. Both curves show very similar tendencies, with the optimum ratio decreasing with frequency. This variation is caused by different rates of change of leakage and active power as a function of the available ranges of supply and threshold voltage needed to achieve a desired frequency. While operating at $100^{\circ} \mathrm{C}$, the chip tolerates a leakage ratio about 3 to 5 percent higher than at $28^{\circ} \mathrm{C}$. Although one could apply more back bias and decrease the leakage power, the penalty in increased switching power would be larger. Abrupt increases in the optimum ratio at the highest frequencies for both temperatures can be attributed to the limited supply voltage range as explained in the previous paragraph.

Figure 7 shows minimum achievable energy per operation vs. frequency for both temperatures (left y-axis). It also gives the ratio of these two energies vs. frequency (right yaxis). Over a wide frequency range, the same performance at $100^{\circ} \mathrm{C}$ requires about 1.5 times the power at $28^{\circ} \mathrm{C}$.

(Energy $\mathrm{x}$ Time) is often considered as metric of choice for low-power applications [11]. In Figure 8, it is plotted vs. supply voltage for the two temperatures. The most optimum (Energy x Time) point for the multiplier operating at $28^{\circ} \mathrm{C}$ occurs at $V_{d d}=0.36 \pm 0.01 \mathrm{~V}, V_{d d}-V_{\text {nwell }}=-0.8 \pm 0.2 \mathrm{~V}$ and $V_{\text {pwell }}=-2 \pm 0.2 \mathrm{~V}$, and is 1.6 times smaller than the lowest (Energy $\mathrm{x}$ Time) value attainable at $100^{\circ} \mathrm{C}$ at $V_{d d}=0.50 \pm 0.01 \quad \mathrm{~V}, \quad V_{d d}-V_{\text {nwell }}=-2 \pm 0.2 \quad \mathrm{~V} \quad$ and $V_{\text {pwell }}=-3 \pm 0.2 \mathrm{~V}$.

\section{CONCLUSIONS}

We have demonstrated that the tuning techniques we previously applied to near-zero threshold CMOS at room temperature also work well at $100^{\circ} \mathrm{C}$. We can still minimize energy at a target operating frequency by adjusting back bias. To achieve the same performance across a wide fre- 


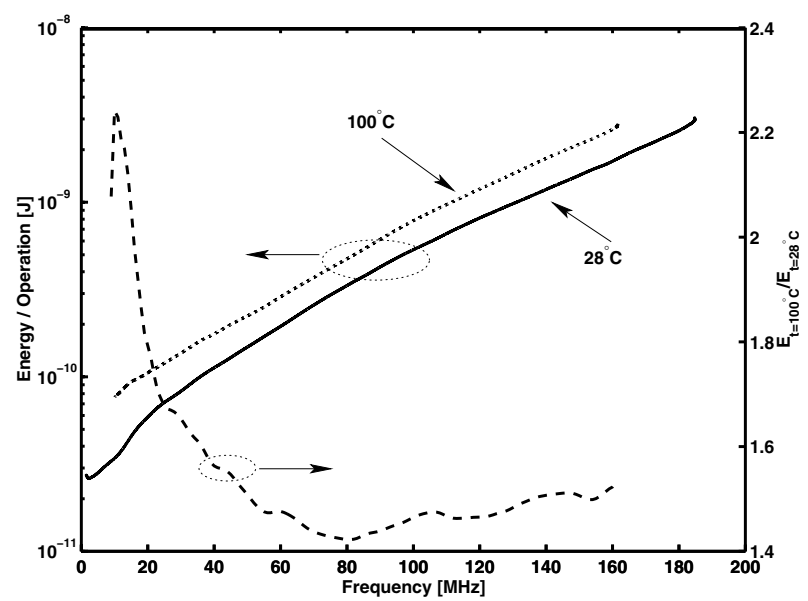

Figure 7: Minimum energy per operation vs. frequency at $28^{\circ} \mathrm{C}$ and $100^{\circ} \mathrm{C}$ (left $\mathrm{y}$-axis) and the ratio of two energies (right y-axis)

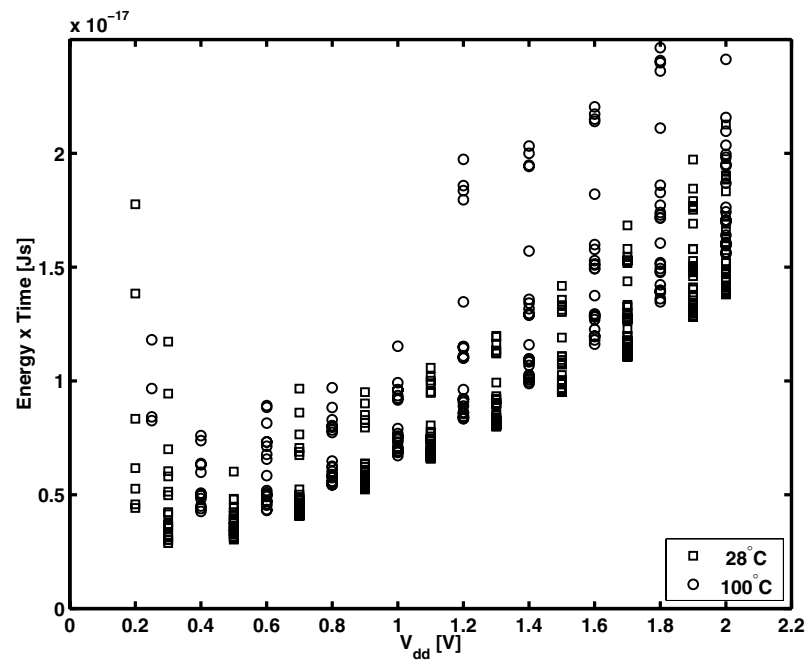

Figure 8: (Energy $\mathrm{x}$ Time) vs. supply voltage at $28^{\circ} \mathrm{C}$ and $100^{\circ} \mathrm{C}$ quency range, the back bias needs to increase about $1.2 \mathrm{~V}$, and the supply voltage needs to increase about 20 percent, increasing the power dissipation by about 1.5 times going from $28^{\circ} \mathrm{C}$ to $100^{\circ} \mathrm{C}$.

\section{ACKNOWLEDGMENTS}

The authors would like to acknowledge Masataka Matsui, Bevan Baas, Jawad Nasrullah, Jim Murguia, Takayasu Sakurai, Sun Microsystems, Toshiba Coorporation and the Department of Defense.

\section{REFERENCES}

[1] J. B. Burr and A. M. Peterson. Ultra low power CMOS technology. In NASA VLSI Design Symposium, pages 4.2.1-4.2.13, October 1991.

[2] Dake Liu and Christer Svensson. Trading speed for low power by choice of supply and threshold voltages. IEEE Journal of Solid-State Circuits, 28(1):10-17, January 1993.

[3] M. Matsui, H. Hara, K. Seta, Y. Uetani, L. Kim, T. Nagamatsu, T. Shimazawa, S. Mita, G. Otomo, T. Oto, Y. Watanabe, F. Sano, Y. Chiba, K. Matsuda, and T. Sakurai. $200 \mathrm{MHz}$ video compression microcells using low-swing differential logic. In IEEE International Solid-State Circuits Conference, pages 72-73, February 1994.

[4] T. Sakurai, H. Kawaguchi, and T. Kuroda. Low power CMOS design through $V_{t h}$ control and low-swing circuits. In International Symposium on Low Power Electronics and Design, pages 1-6, August 1997.

[5] V. Svilan, M. Matsui, J.B. Burr, and T. Sakurai. Energy-efficient $32 \times 32$-bit multiplier in tunable near-zero threshold CMOS. In International Symposium on Low Power Electronics and Design, pages 268-272, August 2000.

[6] J. B. Burr and J. Shott. A $200 \mathrm{mV}$ self-testing encoder/decoder using Stanford Ultra-Low-Power CMOS. In IEEE International Solid-State Circuits Conference, pages 84-85, 1994.

[7] T. Kuroda and T. Sakurai. Threshold-voltage control scheme through substrate-bias for low-power high-speed CMOS LSI design. Journal VLSI Signal Processing Systems, 13(2/3):191-201, Aug./Sept. 1996.

[8] T. Kuroda, K. Suzuki, S. Mita, T. Fujita, F. Yamane, F. Sano, A. Chiba, Y. Watanabe, K. Matsuda, T. Maeda, T. Sakurai, and T. Furuyama. Variable supply-voltage scheme for low-power high-speed CMOS digital design. IEEE Journal of Solid-State Circuits, 33(3):454-462, March 1998.

[9] T. Kuroda. Low power CMOS digital design for multimedia processors. In International Conference on VLSI and CAD, pages 359-367, October 1999.

[10] M. Matsui and J. B. Burr. A Low-Voltage $32 \times 32$-Bit Multiplier in Dynamic Differential Logic. In IEEE Symposium on Low Power Electronics, pages 34-35, October 1995.

[11] Ricardo Gonzalez, B. Gordon, and M. Horowitz. Supply and threshold voltage scaling for low power CMOS. IEEE Journal of Solid-State Circuits, 32(8):1210-1216, August 1997. 